\title{
Pengembangan dan Testing Marker 3D Printed Model pada Aplikasi Augmented Reality Planet Tata Surya
}

\author{
Ika Asti Astuti*, Angga Gusti Mahardika \\ Sistem Informasi, Fakultas Ilmu Komputer, Universitas Amikom, Yogyakarta \\ Jl. Ring Road Utara, Condongcatur, Depok, Sleman, Daerah Istimewa Yogyakarta \\ *Email: asti@amikom.ac.id
}

(received: 19 Juni 2021, revised: 24 Juli 2021, accepted: 29 Agustus 2021)

\begin{abstract}
Abstrak
Teknologi Augmented Reality memungkinkan digunakan untuk menampilkan bentuk 3D objek serta informasi dari sebuah planet dalam tata surya. Pembelajaran tata surya seringkali menggunakan sebuah alat peraga berupa planet-planet berbentuk bulat yang ditempel pada sebuah tiang. Penggunaan marker 3D printed model dimaksudkan untuk memberikan kesan nyata pada marker seperti yang ada pada alat peraga pembelajaran tata surya. Masalah yang mungkin timbul adalah apakah aplikasi dapat mengenali bentuk planet yang memiliki bentuk dasar yang sama (bulat) dan bagaimana efektifitas pengujian marker 3D printed model ini terhadap jarak dan sudut. Maka dari itu, penelitian ini melakukan eksperimen terhadap planet yang memiliki bentuk dasar sama (bulat) untuk melihat apakah aplikasi Augmented Reality yang dibuat dapat mengenali bentuk planet yang diminta, serta eksperimen marker 3D printed model ini terhadap jarak dan sudut deteksi marker. Berdasarkan perolehan point-point yang didapat dari pengujian menunjukkan bahwa persentase marker yang telah diuji berdasarkan sudut dan jarak mempunyai nilai ke akuratan $\geq 50 \%$. Dari segi sudut, semua marker memiliki nilai persentase keakuratan sebesar $100 \%$ sedangkan dari segi jarak, persentase akurasi yang dimiliki mars dan saturnus sama yaitu $50 \%$, yang terakhir bumi memiliki persentase $75 \%$ pada pengujian jarak.
\end{abstract}

Kata kunci: 3d printed model, augmented reality, eksperimen jarak, eksperimen sudut

\begin{abstract}
Augmented reality technology can be used to display $3 D$ shapes of objects and information from a planet in the solar system. Learning the solar system usually uses educational props. The use of $3 D$ printed model markers is intended to give a real impression on markers such as those on solar system learning props. The problem that may arise is whether the application can recognize the shape of the planet that has the same basic shape (spherical) and how effective is the testing of the $3 D$ printed marker model on distances and angles. Therefore, this study conducted experiments on planets that have the same basic shape (spherical) to see if the Augmented Reality application made can recognize the shape of the requested planet, as well as experiments with $3 D$ printed marker models on the distance and angle of marker detection. The results of this study prove that the application can recognize several kinds of planets and each marker has a good marker detection at a certain distance and angle.
\end{abstract}

Keywords: $3 d$ printed model, augmented reality, distance experiment, angle experiment

\section{PENDAHULUAN}

Tata Surya merupakan kumpulan dari benda astronomi (benda langit) yang mempunyai matahari sebagai pusat orbitnya dan dikelilingi oleh beberapa planet yang telah diketahui memiliki satelit dan cirinya sendiri [1]. Pada sistem tata surya terdapat planet yang bergerak mengelilingi matahari dan berjumlah delapan buah antara lain Merkurius, Venus, Bumi, Mars, Yuppiter, Saturnus, Uranus, dan Neptunus. Penggambaran bentuk beberapa planet pada alat peraga biasanya memiliki bentuk yang sama yaitu bulat. Pada sistem pendidikan di Indonesia, tata surya merupakan salah satu materi pelajaran pada ilmu pengetahuan alam yang diajarkan di sekolah dasar yang disesuaikan dengan kurikulum 2013 dimana materi pembelajaran disesuaikan dengan perkembangan teknologi [2]. 
Salah satu metode yang kerap digunakan untuk pembelajaran tata surya yaitu aplikasi Augmented Reality (AR). AR dinilai menjadi salah satu media pembelajaran yang dianggap interaktif dan menarik minat siswa [3][4]. Pada Augmented Reality marker based, memungkinkan untuk menampilkan bentuk 3D objek serta informasi dari marker yang digunakan. Tipe marker pada aplikasi AR yang banyak digunakan pada umumnya terbuat dari sebuah image [5][6][7] . Namun kelemahan dari tipe marker ini yaitu semakin terlihat pixel pada marker, semakin berpengaruh pula pada keberhasilan sistem untuk menampilkan objek [6]. Hal ini terjadi pada resolusi pixel minimum 32x50px yang tidak dapat terdeteksi oleh sistem karena komposisi gambar telah berubah secara signifikan sehingga pola marker yang menjadi image target tidak terlacak dengan semestinya. Sedangkan pada jarak tertentu, marker dengan ukuran 64x100px dan 96x150px dapat terdeteksi oleh sistem. Salah satu solusi yang dapat digunakan untuk menyelesaikan permasalahan ini yaitu penggunaan objek nyata sebagai marker atau pada Augmented Reality dikenal sebagai 3D Object Tracking.

Augmented Reality atau realitas bertambah sebagai penggabungan benda-benda nyata dan maya di lingkungan nyata. Hasilnya ditampilkan secara interaktif dan dalam waktu nyata (real time). Augmented Reality dapat digunakan dalam berbagai kegiatan, seperti presentasi, memperkirakan suatu obyek, peralatan perangsang kinerja, mensimulasikan suatu kinerja alat, dan lain-lain. Beberapa contoh tersebut merupakan gambaran pemanfaatan Augmented Reality secara umum [3]. Fungsi augmented reality adalah untuk menambahkan informasi dan makna pada sebuah 3D Printed Model atau tempat. 3D Printed Model atau ruang dibutuhkan sebagai dasar dan menggabungkan teknologi yang menambahkan data kontekstual untuk memperdalam pemahaman seseorang dari subjek [8].

Perkembangan terbaru dalam membuat sebuah prototyping cepat seperti Printer 3D memungkinkan pengguna untuk membuat prototipe objek sekali pakai dan mengulangi desain [9]. 3D printed model merupakan salah satu teknik yang memungkinkan pengguna dapat mencetak model 3D yang telah dibuat menggunakan software modeling 3D. Blender adalah salah satu software open source yang digunakan untuk membuat konten multimedia khususnya 3D [10]. Hasil printed model memiliki ukuran yang sama dengan hasil desain model 3D. 3D printed model dapat digunakan sebagai marker pada aplikasi Augmented Reality 3D object tracking.

Aplikasi unity 3D adalah game engine merupakan sebuah software pengolah gambar, grafik, suara, input, dan lain-lain yang ditujukan untuk membuat suatu game, meskipun tidak selamanya harus untuk game. Unity dapat digunakan untuk membuat sebuah game yang bisa digunakan pada perangkat komputer, ponsel pintar android, iPhone, PS3, dan bahkan X-BOX [11]. Vuforia adalah Augmented Reality Software Development Kit (SDK) untuk perangkat mobile yang memungkinkan membuat aplikasi Augmented Reality. Dulunya lebih dikenal sebagai QCAR (Qualcomm Company Augmented Reality). Ini menggunakan teknologi Computer Vision untuk mengenali dan melacak gambar planar (Target Image) dan objek 3D sederhana seperti, seperti kotak secara realtime [1].

Penelitian untuk mengukur tingkat akurasi dari penggunaan 3D model di bidang kesehatan telah dilakukan [12]. Namun pengukuran akurasi 3D model sebagai marker pada aplikasi Augmented Reality masih jarang ditemukan. Masalah yang mungkin timbul adalah apakah aplikasi dapat mengenali dan membedakan bentuk planet yang memiliki bentuk dasar yang sama (bulat) dan bagaimana efektifitas pengujian marker 3D printed model ini terhadap jarak dan sudut. Maka dari itu, penelitian ini memiliki 2 fokus utama yaitu: (1) melakukan eksperimen terhadap planet yang memiliki bentuk dasar sama (bulat) untuk melihat apakah aplikasi Augmented Reality yang dibuat dapat mengenali bentuk planet yang diminta, dan (2) melakukan eksperimen efektivitas marker 3D printed model terhadap jarak dan sudut deteksi marker.

\section{TINJAUAN LITERATUR}

Penelitian yang dilakukan oleh [8] menjelaskan tentang dilakukan modifikasi dari single marker menjadi markerless sehingga mampu melakukan scanning tanpa membuat marker atau penanda objek 2D. Pembuatan aplikasi pada penelitian tersebut menggunakan metode single marker dan 3D objek tracking, sedangkan pada penelitian ini menggunakan metode 3D object tracking dengan model realnya berupa miniatur dari bentuk planet tata surya. Teknologi Augmented Reality dapat dimanfaatkan untuk merancang sebuah konsep perpanjangan informasi dari media promosi cetak ke media promosi berbentuk video menggunakan teknologi AR. Sistem yang dibangun mampu 
mengenali marker dan dapat menampilkan video yang di-load melalui URL. Dalam penelitian yang dilakukan oleh Mukhlis, animasi dibangun menggunakan Blender serta proses pembangunan Augmented Reality menggunakan Qualcomm Augmented Reality (QCAR) yang ditampilkan menggunakan smartphone android, aplikasi ini mampu menampilkan objek organ pernapasan manusia yaitu Hidung, Laring, Bronkus, Trakea, dan Paru-Paru serta proses mekanisme dari pernapasan. Hasil ini dapat menjadi solusi alternatif multimedia pembelajaran [13].

Penelitian serupa dilakukan oleh [14], dimana gambar batuan beku dijadikan marker untuk Augmented Reality. Penelitian ini bertujuan untuk membuat sebuah aplikasi AR dan melakukan perbandingan jarak dan waktu kemunculan objek 3D pada gambar marker batuan beku hitam putih dengan marker berwarna. Kesimpulan pada penelitian ini yaitu rentang kecepatan dalam memunculkan objek 3D berkisar antara 0,600 detik hingga 01,063 detik berdasarkan hasil perbandingan dan klasifikasi, marker hitam-putih merupakan jenis marker ideal dalam memunculkan obyek tiga dimensi (3D). Kisaran jarak ideal untuk pemindaian adalah $40 \mathrm{~cm}$ hingga $50 \mathrm{~cm}$, sedangkan pada jarak $10 \mathrm{~cm}$ hingga $25 \mathrm{~cm}$ obyek terlalu dekat dengan kamera dan pada jarak $50 \mathrm{~cm}$ hingga $100 \mathrm{~cm}$ obyek terlalu jauh dari kamera yang membuat obyek tidak dapat dipindai.

[15] melakukan penelitian dengan judul "Aplikasi Edukasi Tata Surya Menggunakan Augmented Reality Berbasis Mobile". Aplikasi ini disertakan dengan Solar AR Book yang berisi informasi tentang tata surya beserta marker untuk menampilkan objek Augmented Reality tata surya. Perbedaan penelitian yang dilakukan yaitu untuk menghasilkan aplikasi yang disertakan dengan Solar AR Book yang berisi informasi tentang tata surya beserta marker untuk menampilkan objek Augmented Reality tata surya, sedangkan penelitian ini menggunakan real object berupa 3D printed model yang berbentuk planet untuk dijadikan marker.

Ismi Naili Qurrotul Aini, Agung Triayudi, dan Ira Diana Sholihati (2020) melakukan penelitian yang berjudul "Aplikasi Pembelajaran Interaktif Augmented Reality Tata Surya Sekolah Dasar Menggunakan Metode Marker Based Tracking”. penelitian ini dibuat untuk membangun aplikasi yang dapat membuat sebuah objek 3D disertai dengan penjelasan, sehingga membuat pembelajaran menjadi lebih interaktif dan mudah dipahami menggunakan teknologi Augmented Reality (AR) [5]. Tujuan penelitian tersebut adalah membangun aplikasi yang dapat membuat sebuah objek 3D dengan metode marker based tracking, sedangkan penelitian ini menggunakan metode 3D Object Tracking.

\section{METODE PENELITIAN}

Metode penelitian yang digunakan dalam penelitian ini yaitu penelitian eksperimental. Adapun alur yang dilakukan dijelaskan pada Gambar 1 .

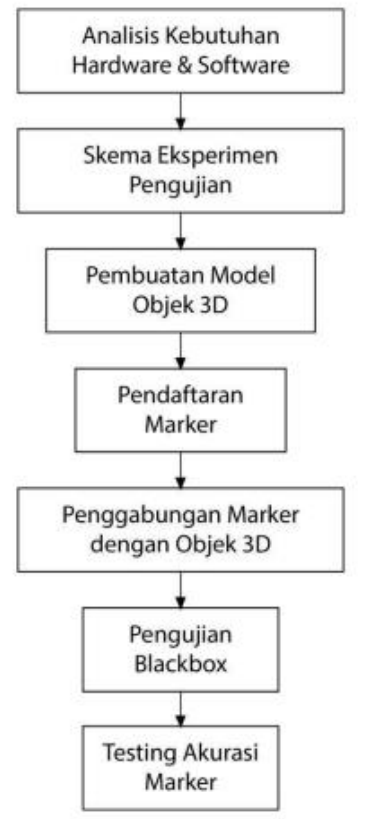

Gambar 1. Metode Penelitian 
Gambar 1 menunjukan tahapan penelitian dari tahap awal sampai tahap akhir. Pada tahap pertama ada "Analisis Kebutuhan Hardware Software", tahap ini merupakan tahap awal dari penelitian yang mana pada tahap ini peneliti melakukan penganalisisan kebutuhan hardware yang dipakai serta software yang digunakan untuk melakukan penelitian ini. Selanjutnya di tahap kedua ada "Skema Eksperimen Pengujian". Pada tahap ini peneliti melakukan pembuatan skema pengujian dari penelitian dari penempatan objek yang akan di scan sebagai marker dan penempatan kamera berdasarkan posisi sudut dan jarak.

Pada tahap ketiga yaitu "Pembuatan Model 3D". Pada tahap ini dilakukan proses pembuatan model 3D melalui software yang ditentukan dan dilakukan printing 3D untuk mendapatkan marker yang akan di scan nantinya. Pada tahap keempat "Pendaftaran Marker", dilakukan pendaftaran marker dari objek 3D yang telah diprint. Pendaftaran marker ini dilakukan agar objek 3D tersebut dapat digunakan sebagai marker pada aplikasi Augmented Reality.

Pada tahap kelima adalah "Penggabungan Marker dan Objek 3D". Tahap ini merupakan langkah terakhir dari pembuatan aplikasi Augmented Reality yang akan dilakukan testing. Setelah aplikasi selesai di build, dilakukan blackbox testing terlebih dulu untuk melakukan pengecekan terhadap fungsi-fungsi dari aplikasi apakah sudah berjalan sesuai yang diharapkan. Tahap terakhir dari penelitian ini adalah "Testing Akurasi Marker" yang didapat dari testing sudut dan jarak objek printed model terhadap smartphone.

\section{HASIL DAN PEMBAHASAN}

\subsection{Analisis Kebutuhan}

\subsubsection{Analisis Kebutuhan Hardware}

Berikut spesifikasi perangkat keras yang dibutuhkan pada perancangan Augmented Reality :

a. Komputer

- Prosesor

: Intel® Core $^{\mathrm{TM}}$ i5-3470

- VGA

- Memory (RAM)

: NVIDIA GeForce GTX $1050 \mathrm{Ti}$

- Hardisk

$: 8 \mathrm{~GB}$

- Mouse

: 500GB

- Monitor

: Logitech

- Kabel Data USB to smartphone

b. Smartphone untuk testing

- Merk

- OS

: Oppo A7

- RAM

: Android

- Versi Android

: 4GB

- Memory Perangkat

$: 8.1 .0$

- Camera

: $64 \mathrm{~GB}$

$: 13+2 \mathrm{MP}$

\subsubsection{Analisis Kebutuhan Software}

Software (perangkat lunak) adalah program aplikasi yang mendukung sistem untuk melengkapi program aplikasi. Perangkat lunak ini digunakan untuk menjalankan perangkat keras. Software yang digunakan juga harus konsisten dengan sistem yang akan dibuat, karena setiap software yang digunakan untuk membuat augmented reality memiliki fungsi yang berbeda-beda. Perangkat lunak yang digunakan meliputi :
a) Blender
b) Unity
c) Vuforia 


\subsection{Skema Eksperimen Pengujian}

Skema Eksperimen Pengujian merupakan skema tata letak objek, camera, sudut, jarak, dan pengujian blackbox untuk pengujian augmented reality yang akan dilakukan pada penelitian ini. Adapun contoh gambar dari skema eksperimen pengujian yang dimaksud seperti pada Gambar 2.

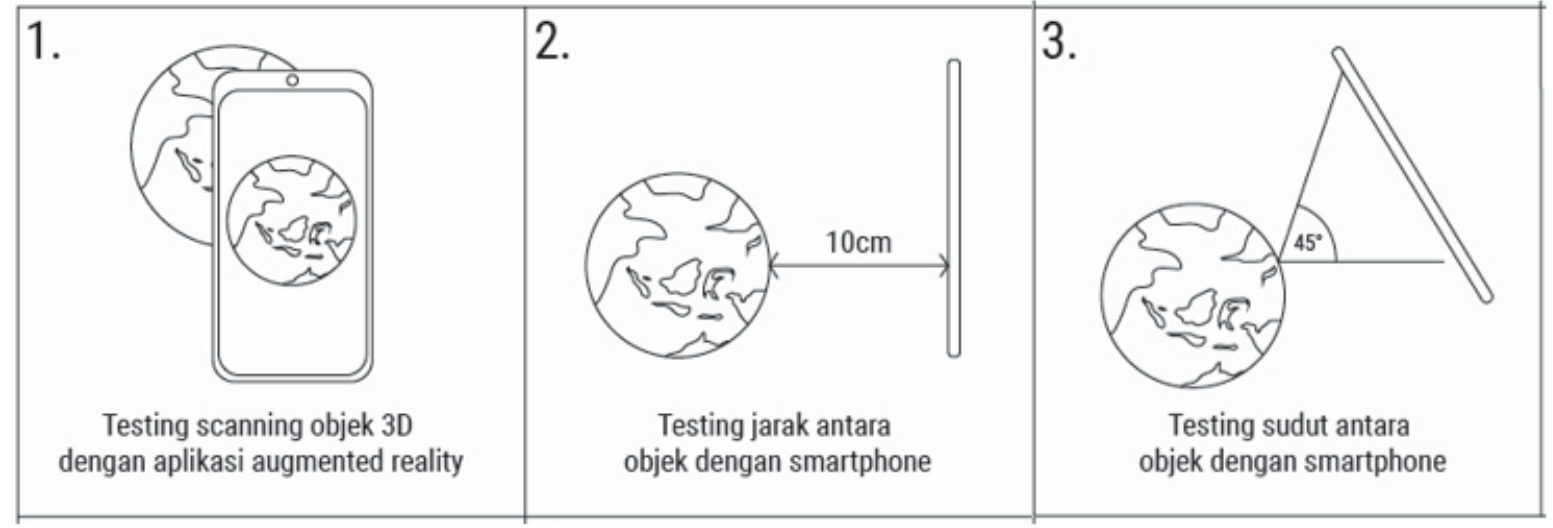

Gambar 2. Skema Eksperimen 3D Printed Model

Dari Gambar 2 dijelaskan bahwa pada skema eksperimen pengujian yang pertama adalah testing scanning objek 3D. eksperimen pengujian tersebut mengacu pada kemampuan aplikasi dalam menscanning objek marker 3D yang telah dibuat, apakah bisa memunculkan visualnya atau tidak. Berikutnya adalah testing jarak antara objek dengan smartphone. Pada eksperimen yang kedua ini adalah peneliti menguji dari jarak berapa terjauh dan terdekatnya agar markernya dapat muncul saat proses scan. Eksperimen yang ketiga adalah menguji marker dengan sudut kamera. sudut kamera yang dipakai adalah $0^{\circ}, 45^{\circ}$ dan $90^{\circ}$. Kesimpulan mencangkup sejumlah data yang diperoleh dari beberapa eksperimen yang telah dilakukan.

\subsection{Pembuatan Model 3D}

Pembuatan model 3D dilakukan agar dapat memperoleh marker yang akan digunakan untuk scanning visualisasi pada augmented reality. Pada tahap ini model objek 3D dibuat menggunakan software / aplikasi "Blender". Objek yang dibuat melalui software tersebut meliputi bentuk planet bumi, mars, dan saturnus. Ilustrasi pembuatan model objek 3D tersebut bisa dilihat seperti Gambar 3 .

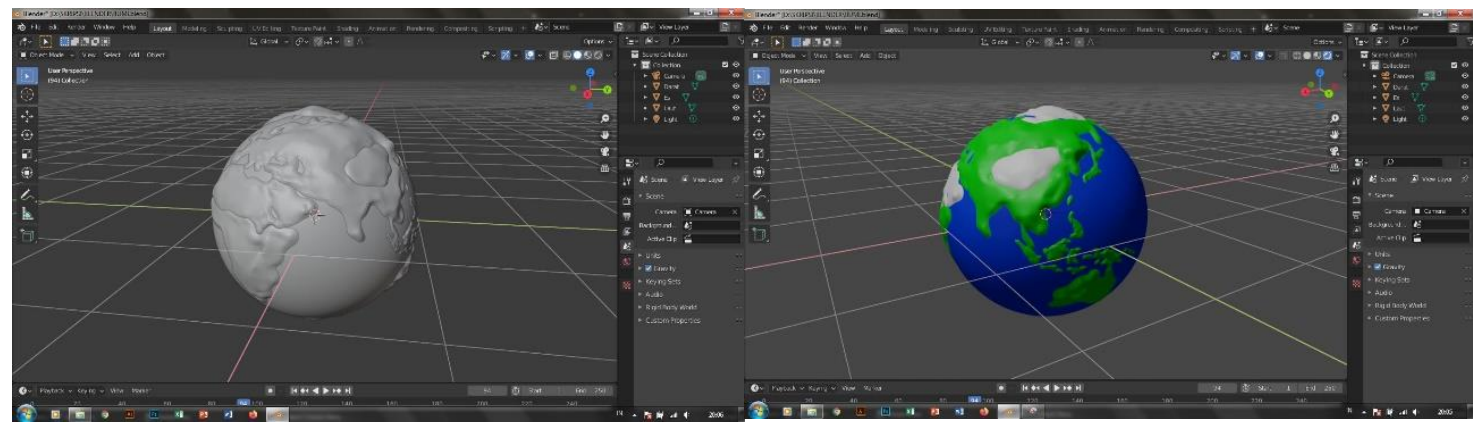

Gambar 3. Pembuatan Model 3D di Blender

Setelah jadi model 3D yang dimaksud, Langkah selanjutnya adalah membuat model objek 3D yang ada pada software tersebut menjadi bentuk nyata. Pembuatan objek digital menjadi bentuk nyata tersebut dilakukan dengan cara 3D printing. Yang mana setelah dicetak dengan 3D printing, objek digital tersebut akan menjadi objek dalam bentuk nyata dan dapat didaftarkan sebagai marker untuk Augmented Reality. Hasil dari objek 3D yang di print menggunakan 3D Printing dapat dilihat pada Gambar 4. 


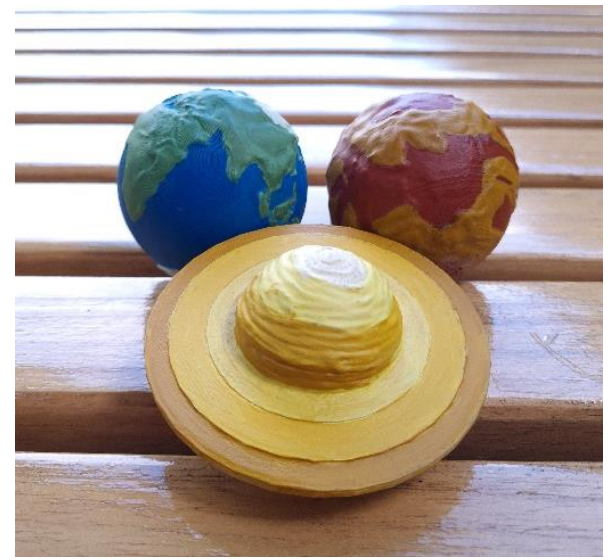

\section{Gambar 4. Hasil Printed Model Bumi, Mars dan Saturnus}

\subsection{Pendaftaran Marker}

Objek 3D yang telah dicetak menjadi bentuk nyata dapat digunakan sebagai marker dengan melalui tahapan pendaftaran sebagai marker yang akan digunakan. Pendaftaran objek menjadi marker Augmented Reality tersebut dapat dilakukan dengan menggunakan software yang didapatkan dari Vuforia. Sebelum masuk ke pendaftaran marker, awalnya menyiapkan beberapa peralatan seperti Device untuk pembuatan marker menjadi database, aplikasi scanning dari Vuforia, kertas dengan print template marker pada vuforia untuk scanning process pembuatan marker dari model 3D.
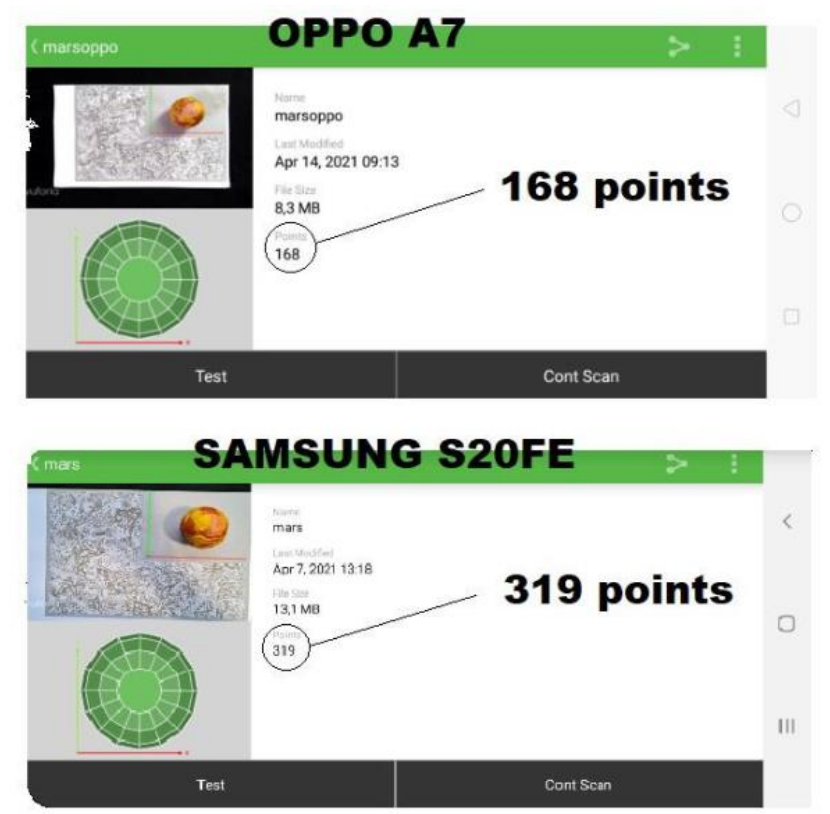

\section{Gambar 5. Proses Point Tracking Menggunakan Smartphone}

Gambar 5 merupakan contoh hasil point yang diperoleh saat proses pendaftaran marker dengan menggunakan device yang berbeda, yang mana perolehan point pada Samsung S20FE mendapat point yang lebih banyak dari oppo A7. Adapun perolehan point tersebut sudah diambil dari hasil yang lebih maksimal dari percobaan-percobaan scanning marker yang telah dibuat sebelumnya dengan alat yang terbatas. 


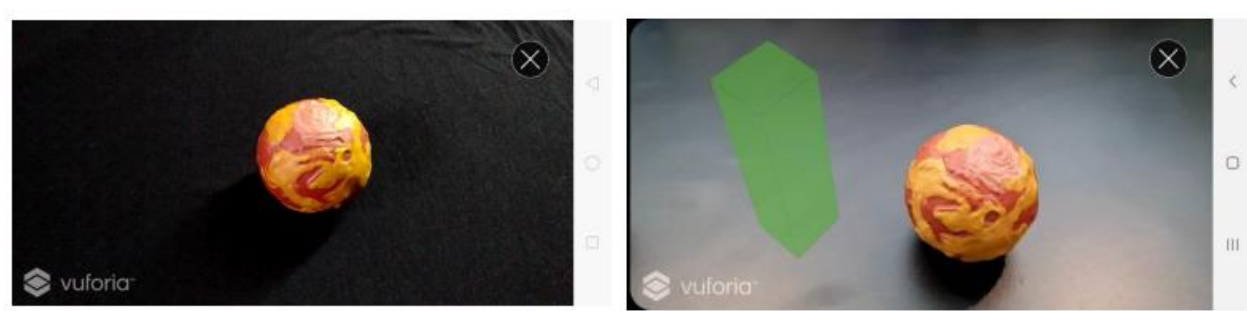
Gambar 6. Testing Hasil Scanning Pembuatan Marker Device Oppo A7 (Kiri) \&
Samsung S20FE (Kanan)

Pada Gambar 6 kiri tidak ditunjukkan adanya objek 3D dari proses scanning dikarenakan point yang didapat hanya sedikit. Hal tersebut terjadi karena kamera pada device Oppo A7 adalah kriteria yang rendah dari yang disarankan oleh vuforia. Pada gambar diatas ditunjukkan adanya objek 3D dari proses scanning. Hal tersebut bisa terjadi karena point yang didapat dari pembuatan marker sebelumnya cukup banyak, meskipun untuk proses scanning dan mendapatkan objek 3D tersebut dikarenakan marker yang dibuat memiliki sedikit tekstur dan peralatan yang dipakai seadanya. Sehingga pada penelitian ini, digunakan hasil point tracking dari Samsung S20FE sebagai database markernya. Marker yang sudah diupload ke Vuforia dan sudah menjadi database akan didownload agar bisa digunakan pada software Unity yang mana nantinya akan diproses dalam pembuatan Augmented Reality.

\subsection{Penggabungan Marker dengan Objek 3D}

Objek yang telah didaftarkan sebagai marker sebelumnya akan diolah lagi. Agar marker tersebut dapat discan dan kemudian mengeluarkan visual di tampilan smartphone, maka dilakukan penggabungan antara marker dengan objek 3D yang telah dibuat melalui software aplikasi blender. Gambar 7 merupakan penggabungan antara marker dengan objek 3D digital tersebut dilakukan menggunakan aplikasi software Unity.

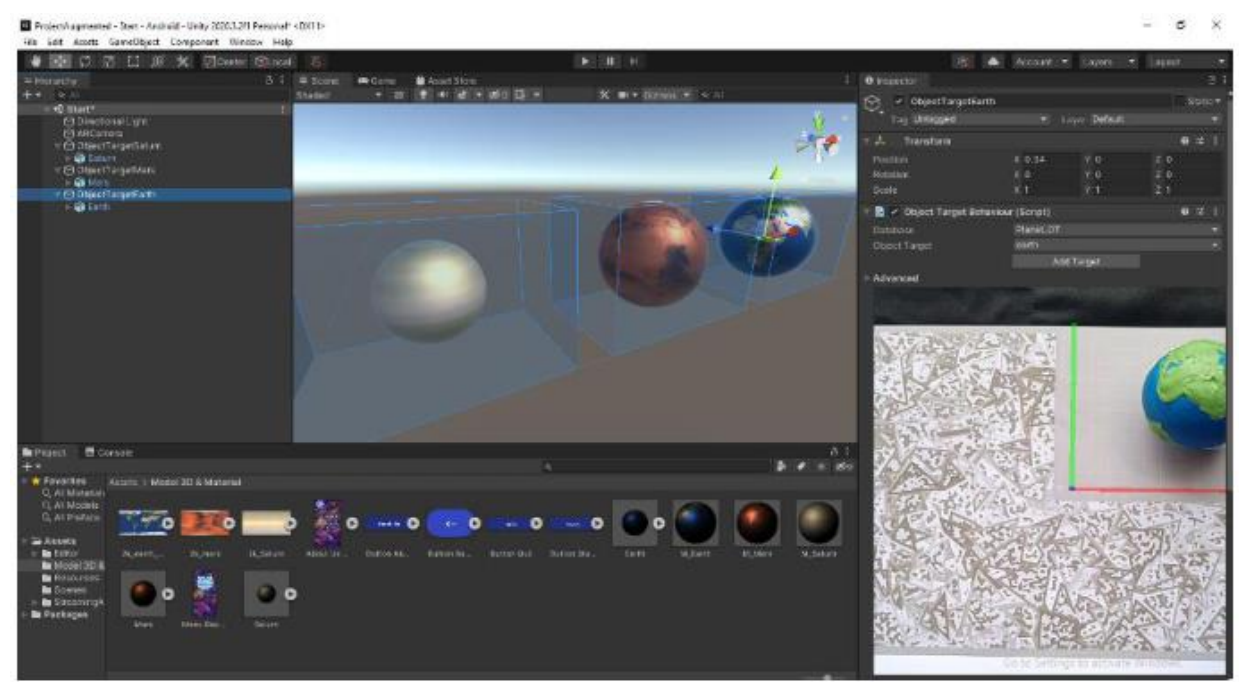

Gambar 7. Penggabungan Object 3D Dengan Marker Pada Unity

Dengan Unity pemrosesan pembuatan augmented reality dilakukan, dari penggabungan marker dengan objek. Setelah selesai melalui semua tahap pemrosesan pembuatan augmented reality tersebut, kemudian Langkah selanjutnya adalah melakukan build application dan jika berhasil tanpa ada error, hasil dari aplikasi tersebut siap diuji coba.

\subsection{Blackbox Testing Aplikasi AR}

Blackbox testing digunakan untuk melihat fungsionalitas aplikasi berdasarkan skenario yang telah dibuat sebelumnya. Pengujian blackbox yang dilakukan digunakan untuk menguji fungsionalitas marker saat dipindai oleh aplikasi yang dijelaskan pada Tabel 1. 
Tabel 1. Blackbox Testing Scan Objek Printed Model

\begin{tabular}{|c|c|c|c|}
\hline Objek yang diuji & Skenario & $\begin{array}{l}\text { Hasil yang } \\
\text { diharapkan }\end{array}$ & Hasil Pengujian \\
\hline Bumi & $\begin{array}{l}\text { Memindai 3D printed model } \\
\text { Bumi }\end{array}$ & $\begin{array}{l}\text { Menampilkan 3D } \\
\text { object Bumi }\end{array}$ & Valid \\
\hline Mars & $\begin{array}{l}\text { Memindai 3D printed model } \\
\text { Mars }\end{array}$ & $\begin{array}{l}\text { Menampilkan 3D } \\
\text { object Mars }\end{array}$ & Valid \\
\hline Saturnus & $\begin{array}{l}\text { Memindai 3D printed model } \\
\text { Saturnus }\end{array}$ & $\begin{array}{l}\text { Menampilkan 3D } \\
\text { object Saturnus }\end{array}$ & Valid \\
\hline Bola Tenis & $\begin{array}{l}\text { Memindai objek lain yang } \\
\text { bukan marker }\end{array}$ & $\begin{array}{l}\text { Tidak menampilkan } \\
\text { 3D object apapun }\end{array}$ & Valid \\
\hline
\end{tabular}

\subsection{Testing Jarak \& Sudut}

Setelah hasil blackbox testing berhasil dilakukan, selanjutnya dilakukan pengujian jarak pada masing-masing 3D printed model sesuai jarak yang telah ditentukan. Hasil testing jarak tersebut dijelaskan pada Tabel 2.

Tabel 2. Pengujian Jarak

\begin{tabular}{lcccc}
\hline 3D Printed Model & $\leq \mathbf{1 0 c m}$ & $\mathbf{1 1 - 5 0 c m}$ & $\mathbf{5 1 - 9 0 c m}$ & $\geq 90 \mathrm{~cm}$ \\
\hline Mars & - & $\checkmark$ & $\checkmark$ & - \\
Bumi & $\checkmark$ & $\checkmark$ & $\checkmark$ & - \\
Saturnus & - & $\checkmark$ & $\checkmark$ & - \\
\hline
\end{tabular}

Dari pengujian yang telah dilakukan dengan jarak sebagai tolak ukurnya menunjukkan bahwa :

a. Marker mars dapat dipindai dengan baik pada jarak $11-90 \mathrm{~cm}$

b. Marker bumi dapat dipindai dengan baik pada jarak $\leq 10 \mathrm{~cm}$ sampai $90 \mathrm{~cm}$

c. Marker Saturnus dapat dipindai dengan baik pada jarak 11-90 cm

Adapun untuk pengujian sudut pada masing-masing 3D printed model dijelaskan pada Tabel 3.

\section{Tabel 3. Pengujian Sudut}

\begin{tabular}{lccc}
\hline 3D Printed Model & $\mathbf{0}^{\circ}$ & $\mathbf{> 4 5}^{\circ}$ & $\mathbf{> 9 0}^{\circ}$ \\
\hline Mars & $\checkmark$ & $\checkmark$ & $\checkmark$ \\
Bumi & $\checkmark$ & $\checkmark$ & $\checkmark$ \\
Saturnus & $\checkmark$ & $\checkmark$ & $\checkmark$ \\
\hline
\end{tabular}

Dari pengujian yang telah dilakukan dengan jarak sebagai tolak ukurnya menunjukkan bahwa :

a. Marker Mars dapat dipindai dengan baik pada sudut $0^{\circ}$ sampai $>90^{\circ}$

b. $\quad$ Marker Bumi dapat dipindai dengan baik pada sudut $0^{\circ}$ sampai $>90^{\circ}$

c. Marker Saturnus dapat dipindai dengan baik pada sudut $0^{\circ}$ sampai $>90^{\circ}$

\subsection{Perhitungan Presentase Akurasi Marker}

Presentase keakuratan marker pada penelitian sebelumnya dilakukan dengan rumus (1) sebagai berikut [17]:

$$
\text { Akurasi }=\frac{\text { Jumlah Berhasil }}{\text { Jumlah Percobaan }} \times 100 \%
$$

Sebelum memulai perhitungan akurasi jarak dan sudut, dilakukan perumusan jumlah percobaan berdasarkan jumlah aspek yang digunakan yang dijabarkan dalam Tabel 4. 
Tabel 4. Jumlah Percobaan Sudut dan Jarak

\begin{tabular}{cccccc}
\hline $\begin{array}{c}\text { Jenis } \\
\text { Pengujian }\end{array}$ & \multicolumn{3}{c}{ Kategori Pengujian } & $\begin{array}{c}\text { Jumlah } \\
\text { Percobaan }\end{array}$ \\
\hline Jarak & $\leq 10 \mathrm{~cm}$ & $11-50 \mathrm{~cm}$ & $51-90 \mathrm{~cm}$ & $\geq 90 \mathrm{~cm}$ & 4 \\
Sudut & $0^{\circ}$ & $45^{\circ}$ & $90^{\circ}$ & - & 3 \\
\hline
\end{tabular}

Jadi perumusan jumlah percobaan dibagi menjadi 2 segi pengukuran, yakni dari segi sudut dan segi jarak. Dari segi sudut sendiri penilaian maksimal 3 dikarenakan dalam segi sudut hanya ada 3 kategori yakni $0^{\circ}, 45^{\circ}$, dan $90^{\circ}$. Sedangkan dari segi jarak penilaiannya maksimal 4 , dikarenakan pada segi jarak ada 4 kategori yakni, $\leq 10 \mathrm{~cm}, 11-50 \mathrm{~cm}, 51-90 \mathrm{~cm}$, dan $\geq 90 \mathrm{~cm}$. Berdasarkan pengujian yang telah dilakukan pada Tabel 2, maka dapat dilakukan perhitungan persentase akurasi marker berdasarkan jaraknya adalah sebagai berikut.

a. Akurasi Jarak Mars $=\frac{2}{4} \times 100 \%=50 \%$

b. Akurasi Jarak Bumi $=\frac{3}{4} \times 100 \%=75 \%$

c. Akurasi Jarak Saturnus $=\frac{2}{4} \times 100 \%=50 \%$

Jadi, pada marker Mars dan Saturnus hasil persentase akurasi jaraknya sama yakni 50\% yang mana ketika dipindai hanya muncul visual 3D augmented realitynya pada jarak $11-50 \mathrm{~cm}$ dan $51-90 \mathrm{~cm}$ saja. Berbeda dengan marker Bumi yang memperoleh persentase akurasi jarak sebesar $75 \%$ yang berhasil dipindai di jarak $\leq 10 \mathrm{~cm}, 11-50 \mathrm{~cm}$, dan $51-90 \mathrm{~cm}$. Berdasarkan pengujian yang telah dilakukan pada Tabel 3, maka dapat dilakukan perhitungan persentase akurasi marker berdasarkan sudutnya adalah sebagai berikut.

a. Akurasi Sudut Mars $=\frac{3}{3} \times 100 \%=100 \%$

b. Akurasi Sudut Bumi $=\frac{3}{3} \times 100 \%=100 \%$

c. Akurasi Sudut Saturnus $=\frac{3}{3} \times 100 \%=100 \%$

Jadi, pada semua marker dari segi sudut akurasinya adalah $100 \%$ yang mana di segala sudut marker dapat terpindai dan muncul visual 3D nya pada aplikasi Augmented Reality. Sehingga kesimpulan hasil persentase akurasi marker berdasarkan jarak dan sudut digambarkan pada Tabel 5.

Tabel 5. Kesimpulan Hasil Presentase Akurasi Marker Berdasarkan Jarak dan Sudut

\begin{tabular}{ccc}
\hline Kriteria & Jarak & Sudut \\
\hline Mars & $50 \%$ & $100 \%$ \\
Bumi & $75 \%$ & $100 \%$ \\
Saturnus & $50 \%$ & $100 \%$ \\
\hline
\end{tabular}

\section{KESIMPULAN}

Penelitian ini berhasil melakukan pengukuran akurasi marker terhadap aplikasi Augmented Reality Planet Tata Surya. Pada tahapan pendaftaran marker ke Vuforia, Pemilihan device yang direkomendasikan oleh Vuforia sangat menentukan hasil scan marker. Untuk membuat aplikasi AR ini juga harus ditentukan bentuk visual yang akan ditampilkan dan sesuai dengan objek 3D nya agar tidak salah dalam penempatan antara visual dengan database marker karena akan terjadi tertukarnya 
antara marker dengan visual 3D pada Augmented Reality. Keakuratan smartphone dalam melakukan scan pada marker tentunya juga berpengaruh dari besar kecilnya objek dan warna yang dijadikan sebagai marker. Dari hasil penelitian bahwa 3D printed model Bumi memiliki keakuratan lebih tinggi dibandingkan Saturnus dan Mars dikarenakan memiliki texture yang cukup detail dan warna yang mencolok. Berdasarkan perolehan point-point yang didapat dari pengujian menunjukkan bahwa persentase marker yang telah diuji berdasarkan sudut dan jarak mempunyai nilai keakuratan $\geq 50 \%$. Dari segi sudut, semua marker memiliki nilai persentase keakuratan sebesar $100 \%$ sedangkan dari segi jarak, presentasi akurasi yang dimiliki mars dan saturnus sama yaitu 50\%, yang terakhir bumi memiliki persentase $75 \%$ pada pengujian jarak. Bagi peneliti selanjutnya, dapat membuat objek 3D yang akan dijadikan sebagai marker harus bertekstur dengan bentuk dan warna yang jelas agar mendapatkan $>300$ point. Hal tersebut ditujukan supaya dalam melakukan pemindaian dalam aplikasi augmented reality nya cepat menampilkan visual dan mudah. Dalam pembuatan marker (proses memindai objek 3D) harus dilakukan dengan pencahayaan yang cukup. Peneliti selanjutnya juga dapat membuat penelitian dengan tema yang sama untuk meneruskan penambahan detail jarak dan sudut yang digunakan agar hasil penelitian menjadi lebih detail.

\section{REFERENSI}

[1] S. D. Y. Kusuma, "Perancangan Aplikasi Augmented Reality Pembelajaran Tata Surya dengan Menggunakan Marker Based Tracking," J. Inform. Univ. Pamulang, vol. 3, no. 1, p. 33, 2018, doi: 10.32493/informatika.v3i1.1428.

[2] H. F. Santi and I. A. Astuti, "Pembuatan Prototype Aplikasi Game Edukasi Sistem Tata Surya Untuk Siswa Sekolah Dasar," J. Inf. Syst. Manag., vol. 1, no. 2, pp. 6-10, 2020, doi: 10.24076/joism.2020v1i2.25.

[3] L. Hakim, "Pengembangan Media Pembelajaran Pai Berbasis Augmented Reality," Lentera Pendidik. J. Ilmu Tarb. dan Kegur., vol. 21, no. 1, pp. 59-72, 2018, doi: 10.24252/lp.2018v21n1i6.

[4] S. Wardani, "Pemanfaatan Teknologi Augmented Reality ( Ar )," J. Teknol., vol. 8, no. 2, pp. 104-111, 2015, [Online]. Available: https://ejournal.akprind.ac.id/index.php/jurtek/article/view/1119.

[5] I. N. Q. Aini, A. Triayudi, and I. D. Sholihati, "Aplikasi Pembelajaran Interaktif Augmented Reality Tata Surya Sekolah Dasar Menggunakan Metode Marker Based Tracking," J. Media Inform. Budidarma, vol. 4, no. 1, p. 178, 2020, doi: 10.30865/mib.v4i1.1875.

[6] A. Syahrin, M. E. Apriyani, and S. Prasetyaningsih, "Analisis Dan Implementasi Metode Marker Based Tracking Pada Augmented Reality Pembelajaran Buah-Buahan," Komputa J. Ilm. Komput. dan Inform., vol. 5, no. 1, pp. 11-17, 2016, doi: 10.34010/komputa.v5i1.2433.

[7] A. Nugroho and B. A. Pramono, "Aplikasi Mobile Augmented Reality Berbasis Vuforia Dan Unity Pada Pengenalan Objek 3D Dengan Studi Kasus Gedung M Universitas Semarang," J. Transform., vol. 14, no. 2, p. 86, 2017, doi: 10.26623/transformatika.v14i2.442.

[8] R. A. Setyawan and A. Dzikri, "Analisis Penggunaan Metode Marker Tracking Pada Augmented Reality Alat Musik Tradisional Jawa Tengah," Simetris J. Tek. Mesin, Elektro dan Ilmu Komput., vol. 7, no. 1, p. 295, 2016, doi: 10.24176/simet.v7i1.517.

[9] S. Mueller, S. Im, S. Gurevich, A. Teibrich, F. Guimbretière, and P. Baudisch, "WirePrint: Fast 3D Printed Previews," Proced. UIST 2014, no. Figure 2, pp. 273-280, 2014.

[10] E. Ardhianto, "Augmented Reality Objek 3 Dimensi dengan Perangkat Artoolkit dan Blender," Din. Teknol. ..., vol. 17, no. 2, pp. 107-117, 2012, [Online]. Available: http://www.unisbank.ac.id/ojs/index.php/fti1/article/view/1658.

[11] I. Bagus and M. Mahendra, "Implementasi Augmented Reality ( Ar ) Menggunakan Unity 3D Dan Vuporia Sdk," J. Ilm. ILMU Komput. Univ. Udayana, vol. 9, no. 1, pp. 1-5, 2016.

[12] E. George, P. Liacouras, F. J. Rybicki, and D. Mitsouras, "Measuring and establishing the accuracy and reproducibility of 3D printed medical models," Radiographics, vol. 37, no. 5, pp. 1424-1450, 2017, doi: 10.1148/rg.2017160165.

[13] R. E. Saputro and D. I. S. Saputra, "Pengembangan Media Pembelajaran Mengenal Organ Pencernaan Manusia Menggunakan Teknologi Augmented Reality," J. Buana Inform., vol. 6, no. 2, pp. 153-162, 2015, doi: 10.24002/jbi.v6i2.404. 
[14] G. I. Saputram, Kadek Surya Adi, Gede Aris Gunadi, "Analisis Pengaruh Jenis Marker Pada Kualitas Augmented Reality Batuan Beku Dengan Metode Marker-Based Tracking," vol. 6, no. 1, pp. 1-8, 2021.

[15] C. A. Sugianto, "Aplikasi Edukasi Tata Surya Menggunakan Augmented Reality Berbasis Mobile,” 2018, doi: 10.31227/osf.io/swun9. 